\title{
Evaluasi Penerimaan Modul Kepegawaian SIESTA Menggunakan Model UTAUT2
}

\author{
Shafira Rahmi Supriyanto ${ }^{1}$, Dwi Rolliawati ${ }^{2}$, Nita Yalina ${ }^{3}$. \\ 1,2,3 Program Studi Sistem Informasi, Universitas Islam Negeri Sunan Ampel \\ email: shafira.rahmi847@gmail.com ${ }^{1}$,dwi_roll@uinsby.ac.id ${ }^{2}$, nitayalina@uinsby.ac.id ${ }^{3}$
}

(Received: 15 Maret 2020/ Accepted: 29 April 2020/ Published Online: 20 Juni 2020)

\begin{abstract}
Abstrak
Keberhasilan penerapan teknologi informasi sebagian besar bergantung pada level penerimaan masing-masing individu pengguna. Oleh sebab itu, dibutuhkan interpretasi serta estimasi yang tepat agar penerimaan user dapat ditingkatkan. Sebagian pengguna modul Kepegawaian SIESTA kesulitan dalam menggunakan sistem ini mendukung dilakukannya penelitian dari segi penerimaan sistem. Tujuan dari penelitian ini agar dapat memahami aspek-aspek yang memiliki dampak terhadap penerimaan modul Kepegawaian SIESTA dengan model UTAUT2 hingga pihak RSUD Dr. Soetomo Surabaya dapat memanfaatkan hasil penelitian dalam mengembangkan dan menerapkan modul-modul SIESTA. Data dikumpulkan berasal dari kuesioner 359 pegawai ditentukan dengan teknik disproportionate stratified random sampling. Metode yang digunakan yakni kuantitatif dengan teknik SEM-PLS. Hasil penelitian ditemukan aspek yang berdampak signifikan yaitu social influence, price value, facilitating conditions, serta habit. Aspek behavioral intention dipengaruhi oleh social influence dan price value, serta facilitating conditions dan habit terhadap aspek use behavior. Sementara tidak satupun dari aspek moderator age, gender, dan experience memperkuat dampak aspek penerimaan. Dapat disimpulkan terdapat empat aspek yang berdampak terhadap penerimaan modul Kepegawaian SIESTA dengan tanpa diperkuat aspek moderator.
\end{abstract}

Kata kunci: Disproportionate Stratified Random Sampling, Penerimaan Sistem, SEM-PLS, UTAUT2

\begin{abstract}
The successful application of information technology largely depends on the level of acceptance of each user. Therefore, accurate interpretation and estimation are needed so that user acceptance can be increased. Some users of the modul Kepegawaian SIESTA have difficulty using this system to support research in terms of system acceptance. The purpose of this research is to be able to understand aspects that have an impact on the acceptance of the modul Kepegawaian SIESTA with the UTAUT2 model up to the RSUD Dr. Soetomo Surabaya can utilize research results in developing and implementing SIESTA modules. Data collected from 359 employee questionnaires were determined by disproportionate stratified random sampling technique. The method used is quantitative with SEM-PLS technique. The results of the study found aspects that have a significant impact, namely social influence, price value, facilitating conditions, and habit. Behavioral intention aspects are influenced by social influence and price value, as well as facilitating conditions and habit regarding aspects of use behavior. While none of the moderator aspects of age, gender, and experience strengthen the impact of the acceptance aspect. It can be concluded that four aspects have an impact on the acceptance of the modul Kepegawaian SIESTA without being strengthened by the moderator aspect.
\end{abstract}

Keywords: Disproportionate Stratified Random Sampling, SEM-PLS, System Acceptance, UTAUT2

\section{PENDAHULUAN}

Pada era modern yang berkembang pesat seperti saat ini mendorong setiap instansi untuk menerapkan teknologi informasi (TI) dalam menjalankan proses bisnisnya agar lebih efisien dan lebih efektif. Namun, proses pengimplementasian TI tidak selalu berjalan sesuai 
ekspektasi, mulai dari proses desain, penyampaian, hingga TI tersebut digunakan. Hal itu dibuktikan dengan penelitian yang menunjukkan bahwa proyek TI berskala besar hanya dapat memberikan 56\% dari manfaat yang dijanjikan (Bloch, Blumber, \& Laartz, 2012). Selain itu, disebutkan bahwa kesuksesan implementasi TI dan perilaku user dalam menerima TI berhubungan secara signifikan (Quadahi, 2008). Berhasilnya penerapan suatu TI sebagian besar tergantung pada level penerimaan dan penggunaan tiap pribadi penggunanya. Oleh karenanya, dibutuhkan penafsiran serta perkiraan agar penerimaan user dapat ditingkatkan dengan merubah karakteristik sistem dan prosedur penerapan yang dipakai.

RSUD Dr. Soetomo Surabaya ialah instansi rumah sakit terbesar Wilayah Indonesia Bagian Timur dengan pegawai berjumlah 2.797 orang. Hal mengenai pencatatan dan pelaporan data dari tiap pegawai adalah fungsi modul Kepegawaian SIESTA. Hasil observasi sesaat yang dilakukan pada 20 pegawai, 10 orang menyatakan bahwa mereka kesulitan dalam menggunakan sistem ini. Penggunaan sistem tersebut juga dibatasi, pegawai hanya dapat mengakses sistem saat berada di dalam lingkungan rumah sakit. Dengan adanya masalah tersebut, maka penting diukur penerimaan modul Kepegawaian SIESTA yang belum pernah diteliti sebelumnya.

Terdapat suatu model penerimaan teknologi yang berasal dari penggabungan 8 model penerimaan yakni The Unified Theory of Acceptance and Use of Technology (UTAUT). Model-model tersebut diantaranya Technology Acceptance Model (TAM), Motivation Model (MM), Model of PC Utilization (MPCU), Innovation Diffussion Theory (IDT), Social Cognitive Theory (SCT), Theory of Reasoned Action (TRA), Theory of Planned Behavior (TPB), Combined Technology Acceptance Model and Theory of Planned Behavior (C-TAMTPB). UTAUT lebih unggul dari 8 model lain dalam mengetahui minat penggunaan suatu TI dan dapat memaparkan hingga 70\% varian user (Venkatesh, Morris, Davis, \& Davis, 2003). Model UTAUT2 ialah perkembangan dari UTAUT, tampilannya mampu ditinjau dalam Gambar 1.

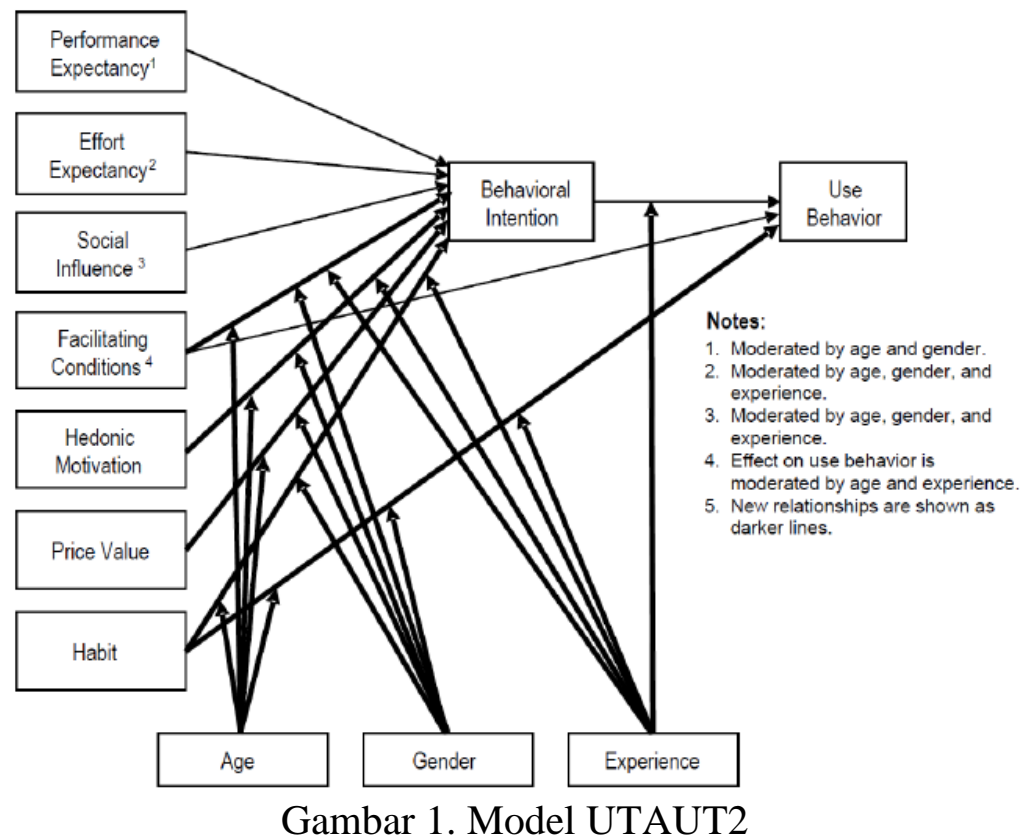

Gambar 1 adalah tampilan model UTAUT2, terdapat tujuh aspek inti dan tiga aspek moderator diantaranya performance expectancy, effort expectancy, social influence, facilitating conditions, hedonic motivation, price value, dan habit. Aspek-aspek tersebut dimoderasi oleh tiga aspek moderasi age, gender, serta experience. (Venkatesh, Thong, \& $\mathrm{Xu}, 2012$ ). Baik UTAUT atau UTAUT2 memiliki jumlah aspek moderator paling banyak 
diantara 8 model gabungan lainnya yang dapat berdampak signifikan terhadap nilai varians $R^{2}$ (Samaradiwakara \& Gunawardena, 2014). Berikut rincian jumlah aspek moderator beserta nilai varians $R^{2}$ model-model gabungan: TAM, TRA, TPB sebesar $0.53 ; 0.36 ; 0.47$ dengan dua aspek. MPCU, IDT, C-TAM-TPB sebesar 0.47; 0.40; 0.39 dengan satu aspek. Serta MM dan SCT sebesar 0.38 dan 0.36 tanpa aspek moderator. Berdasarkan rincian nilai varians $R^{2}$ tertinggi adalah nilai model TAM sebesar 0.53. Sementara nilai model UTAUT bernilai 0.69, berarti bernilai tertinggi diantara delapan model lain. Dengan demikian, digunakan UTAUT2 dalam mengukur penerimaan modul Kepegawaian SIESTA.

Penelitian pertama terkait UTAUT adalah penelitian terhadap layanan Internet of Things (IoT) yang belum diimplementasikan di pasaran (Wonjun \& Shin, 2019). Penelitian kedua menggunakan model UTAUT2 dalam mengukur penerimaan aplikasi mobile messaging tanpa melibatkan aspek moderator (Mutlu \& Der, 2017). Penelitian terakhir yaitu tentang layanan mobile banking kuesioner yang digunakan kurang relevan (Pertiwi \& Ariyanto, 2017). Dari ketiga penelitian tersebut, maka perbaikan yang dilakukan ialah pertanyaan dari item survei model UTAUT2 dan disesuaikan dengan sistem. Selain itu, penelitian ini juga melibatkan aspek moderator untuk meneliti penerimaan modul Kepegawaian SIESTA yang berjalan.

Hasil penelitian ini bertujuan agar dapat bermanfaat menjadi feedback serta sebagai kontribusi bagi pihak RSUD Dr. Soetomo Surabaya dalam memahami aspek-aspek yang mempengaruhi penerimaan modul Kepegawaian SIESTA berdasarkan model UTAUT2. Sehingga diharapkan sifat sistem dan proses implementasi yang digunakan terhadap modulmodul SIESTA dapat diubah sesuai dengan penerimaan $u s e r$.

\section{METODE PENELITIAN}

Metode yang dipakai yaitu kuantitatif dengan teknik Structural Equation ModelingPartial Least Square (SEM-PLS). Suatu penelitian di Jerman tentang penerimaan berdasarkan model UTAUT dengan membandingkan beberapa event menggunakan teknik analisis korelasi sebagai metode penelitiannya (Geldmacher, Just, Kirschner, Buchmuller, \& Marquardt, 2017). Disarankan pada penelitian selanjutnya agar menggunakan SEM sebagai metode. Populasi pada penelitian ini adalah seluruh pegawai RSUD Dr. Soetomo Surabaya serta sampel ditetapkan dengan disproportionate stratified random sampling pada tiap kategori pegawai dokter, tenaga perawat, dan tenaga profesional lain. Data dikumpulkan melalui survei kuesioner berisi pertanyaan dari item survei pada model penelitian UTAUT2 dengan mencakup seluruh aspek (Venkatesh et al., 2012). Indikator-indikator tiap aspek diantaranya:

1. Performance expectancy (PE). Indikator: perceived usefulness (PE1), extrinsic motivation (PE2), job fit (PE3), dan relative advantage (PE4).

2. Effort expectancy (EE). Indikator: perceived ease of use (EE1), complexity (EE2), dan ease of use (EE3).

3. Social influence (SI). Indikator: subjective norm (SI1), social factor (SI2), dan image (SI3).

4. Facilitating conditions (FC). Indikator: perceived behavioral control (FC1), facilitating conditions (FC2), dan compatibility (FC3).

5. Hedonic motivation (HM). Indikator: fun (HM1), entertain (HM2), dan interest (HM3).

6. Price value (PV). Indikator: quality (PV1), price (PV2), dan value (PV3).

7. Habit $(\mathrm{Hb})$. Indikator: prior use $(\mathrm{Hb} 1)$, addiction $(\mathrm{Hb} 2)$, dan behavior to be automatic ( $\mathrm{Hb} 3)$.

8. Behavioral intention (BI). Indikator: repurchase intentions (BI1), positive word-of-mouth communication (BI2), dan service quality (BI3). 
9. Use behavior (UB). Indikator: usage time (UB1), usage frequency (UB2), dan use variety (UB3).

Pertanyaan kuesioner menggunakan skala Likert dengan alternatif jawaban 1: 'Sangat tidak setuju (STS)', 2: 'Tidak setuju (TS)', 3: 'Cukup setuju (CS)', 4: 'Setuju (S)', dan 5: 'Sangat setuju (SS)'. Setelah kuesioner terkumpul, data dianalisis menggunakan teknik SEM-PLS dengan bantuan software SmartPLS 3.0. Tahapan dimulai dari pengujian outer model (model pengukuran), inner model (model struktural), hingga uji hipotesis.

Analisis outer model yakni memvisualkan relasi antara peubah laten beserta variabel manifesnya. Caranya adalah dengan mengevaluasi validitas (konvergen dan diskriminan) serta reliabilitas (composite realibility dan Cronbach's Alpha). Fungsi validitas konvergen yaitu agar didapati mewakili dan mendasari tidaknya suatu indikator terhadap peubah laten. Sedangkan validitas diskriminan berfungsi mengetahui apakah indikator satu dengan lainnya berbeda. Kedua uji reliabilitas berfungsi sama untuk mengukur reliabilitas instrumen.

Analisis inner model digunakan guna mengevaluasi serta melihat signifikansi relasi kausalitas masing-masing peubah laten. Tahapan yang dilakukan yaitu dengan melihat nilai $R$-Square atau coefficient determinant, $Q$-Square $\left(Q^{2}\right)$, dan pengujian effect size $\left(f^{2}\right)$. Selain itu juga dapat menggunakan nilai path coefficient untuk memprediksi hubungan variabel laten.Tahap pengujian hipotesis dilaksanakan melalui metode bootstrapping. Tingkatan signifikansi diterimanya hipotesis mampu dipakai nilai $T$ Statistic atau $p$ values. Jika skor $T$ Statistic lebih besar daripada skor $T$ Table atau $p$ value bernilai 0.000 , maka hipotesis diterima. Hipotesis yang diuji mampu ditinjau dalam Tabel 1.

Tabel 1. Hipotesis Statistik

\begin{tabular}{cc}
\hline Hipotesis & Rumusan \\
\hline H1 & PE berdampak positif pada BI secara signifikan \\
H2 & EE berdampak positif pada BI secara signifikan \\
H3 & SI berdampak positif pada BI secara signifikan \\
H4 & FC berdampak positif pada BI secara signifikan \\
H5 & HM berdampak positif pada BI secara signifikan \\
H6 & PV berdampak positif pada BI secara signifikan \\
H7 & Hb berdampak positif pada BI secara signifikan \\
H8 & FC berdampak positif pada UB secara signifikan \\
H9 & Hb berdampak positif pada UB secara signifikan \\
H10 & BI berdampak positif pada UB secara signifikan \\
H11 & Age, gender, dan experience memperkuat dampak FC pada BI \\
H12 & Age, gender, dan experience memperkuat dampak HM pada BI \\
H13 & Age dan gender memperkuat dampak PV pada BI \\
H14 & Age, gender, dan experience memperkuat dampak Hb pada BI \\
H15 & Age, gender, dan experience memperkuat dampak Hb pada UB \\
\hline
\end{tabular}

Setelah diketahui hipotesis yang diterima dan ditolak, dapat disusun kesimpulan dan saran yang dapat dilakukan untuk meningkatkan penerimaan berdasarkan tiap aspek yang berdampak.

\section{HASIL DAN PEMBAHASAN \\ Deskripsi Obyek Penelitian}

Total populasi pada penelitian ini berjumlah 2.797 orang. Berdasarkan kalkulasi rumus Slovin dengan error tolerance 5\%, sampel yang dibutuhkan yaitu 350. Sementara besar sampel tiap kategori yaitu dokter sebesar 79 sampel, tenaga perawat 241 sampel, dan tenaga 
profesional lain 40. Setelah dilakukan penyebaran terhadap 360 kuesioner, ada satu kuesioner yang tidak memenuhi hingga data yang dipakai sebanyak 359 .

Berdasarkan tampilan gambar model UTAUT2, variabel independen pada penelitian ini yakni aspek performance expectancy, effort expectancy, social influence, facilitating conditions, hedonic motivation, price value, serta habit. Sementara behavioral intention dan use behavior sebagai variabel dependen. Aspek moderator sebagai variabel moderasi yaitu age dengan indikator usia (tahun), gender dengan jenis kelamin (L/P), serta experience terdiri dari dua indikator yakni masa kerja (tahun) dan pendidikan terakhir (diploma/S1/S2/S3). Tampilan rancangan model penelitian dapat diperhatikan dalam Gambar 2. Pada Gambar 2 dapat diketahui Jumlah indikator tiap variabel berbeda-beda, tergantung jumlah indikator tiap aspek. Contohnya pada aspek performance expectancy (PE): indikator PE1 merupakan perceived usefulness, indikator PE2 yakni extrinsic motivation, indikator PE3 job fit, dan indikator PE4 mewakili relative advantage.

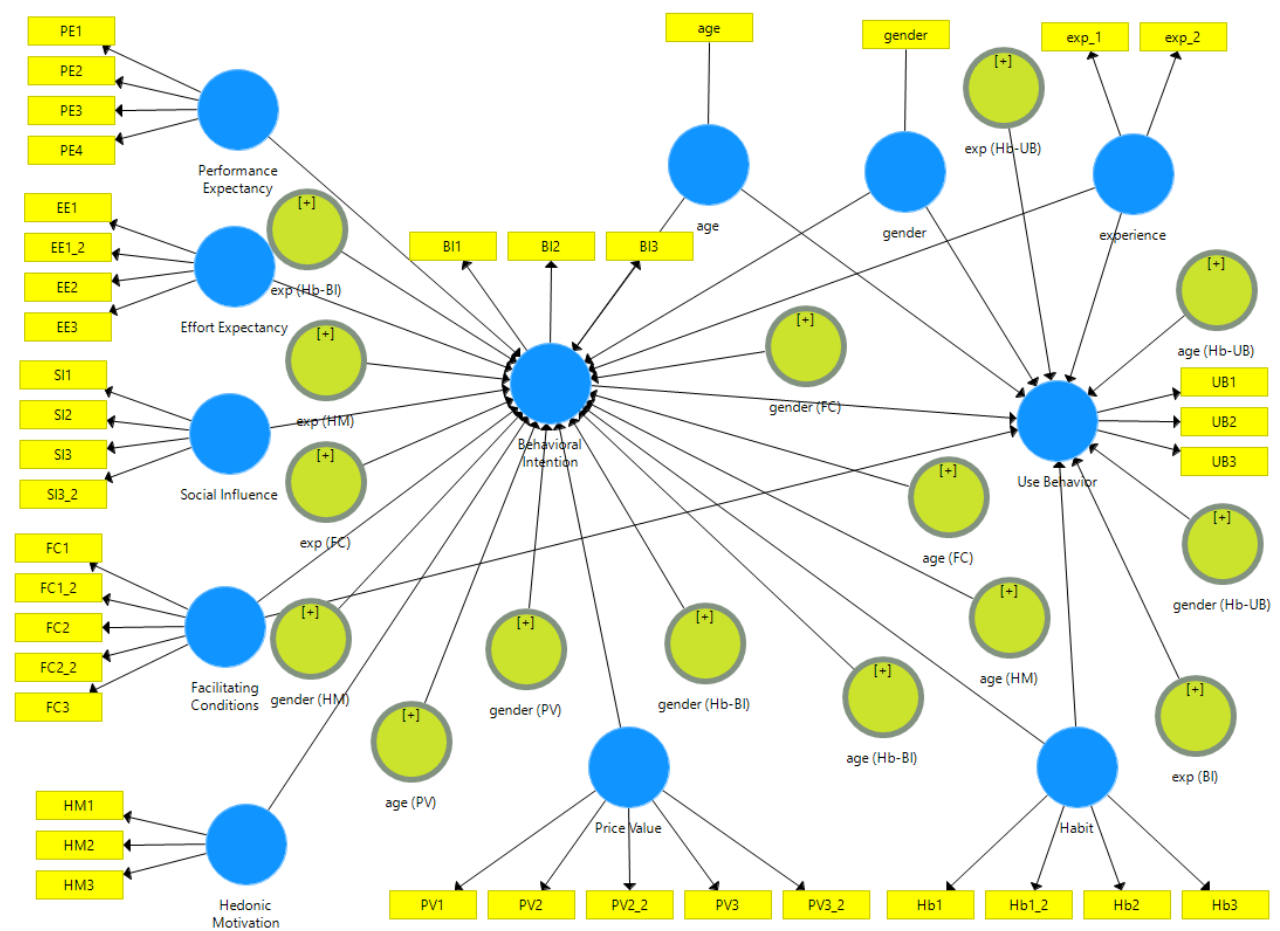

Gambar 2. Rancangan Model Pada SmartPLS

\section{Analisis Pengujian Validitas Konvergen}

Convergent validity dapat diukur dari skor standardized loading factor (outer loading) atau besaran korelasi yang dikeluarkan oleh variabel indikator. Ukuran refleksif individual dinyatakan baik jika skor loading factor 0,5-0,6 dikira cukup dalam awal penelitian (Ghozali, 2014). Tiap skor outer loadings melampaui syarat yaitu lebih dari 0,5. Daftar indikator lengkap beserta nilai outer loading mampu ditinjau dalam Tabel 2. Dapat diketahui indikator exp_2 (pendidikan terakhir) bernilai 0.238 sehingga harus dihapus karena dibawah 0,5. Setelah dihapus, terdapat perubahan pada beberapa nilai outer loadings yang indikatornya berhubungan dengan experience, kecuali indikator behavioral intention behavioral intention * experience. Dengan demikian seluruh indikator dinyatakan melewati uji validitas dengan nilai terendah 0.714 pada indikator PV3_2. 
Tabel 2. Nilai Outer Loadings (Loading Factor)

\begin{tabular}{cccc}
\hline Indikator & Outer Loadings & Indikator & Outer Loadings \\
\hline PE1 & 0.737 & PV2_2 & 0.838 \\
PE2 & 0.863 & PV3 & 0.859 \\
PE3 & 0.824 & PV3_2 & 0.714 \\
PE4 & 0.835 & $\mathrm{Hb} 1$ & 0.874 \\
EE1 & 0.814 & $\mathrm{Hb} 1 \_2$ & 0.853 \\
EE1_2 & 0.828 & $\mathrm{Hb} 2$ & 0.831 \\
EE2 & 0.833 & $\mathrm{Hb3}$ & 0.835 \\
EE3 & 0.843 & $\mathrm{BI} 1$ & 0.863 \\
SI1 & 0.829 & $\mathrm{BI}$ & 0.860 \\
SI2 & 0.838 & $\mathrm{BI3}$ & 0.865 \\
SI3 & 0.807 & $\mathrm{UB} 1$ & 0.814 \\
SI3_2 & 0.764 & $\mathrm{UB} 2$ & 0.886 \\
FC1 & 0.760 & $\mathrm{UB} 3$ & 0.844 \\
FC1_2 & 0.819 & age & 1.000 \\
FC2 & 0.789 & gender & 1.000 \\
FC2_2 & 0.796 & exp_1 & $0.990->1.000$ \\
FC3 & 0.847 & exp_2 & $\mathbf{0 . 2 3 8}$ \\
HM1 & 0.791 & Facilitating Conditions $*$ experience & $1.018->1.033$ \\
HM2 & 0.857 & Hedonic Motivation * experience & $1.108->1.105$ \\
HM3 & 0.866 & Habit * experience (Hb-BI) & $1.002->1.029$ \\
PV1 & 0.805 & Habit * experience $($ Hb-UB) & $1.002->1.029$ \\
PV2 & 0.834 & Behavioral Intention * experience & 1.095 \\
\hline
\end{tabular}

\section{Analisis Pengujian Validitas Diskriminan dan Reliabilitas Konstruk}

Discriminant validity mampu diukur melalui pengkomparasian skor square root of average variance extracted (AVE) yang dikeluarkan oleh tiap peubah laten. Begitu pula pengujian reliabilitas, keduanya dihasilkan peubah laten. Daftar variabel secara lengkap beserta skor AVE, composite reliability, dan Cronbach's Alpha mampu ditinjau dalam Tabel 3.

Tabel 3. Skor AVE, Composite Reliability, dan Cronbach's Alpha

\begin{tabular}{cccc}
\hline Variabel & AVE & Composite Reliability & Cronbach's Alpha \\
\hline Performance Expectancy & 0.666 & 0.888 & 0.832 \\
Effort Expectancy & 0.688 & 0.898 & 0.849 \\
Social Influence & 0.656 & 0.884 & 0.825 \\
Facilitating Conditions & 0.644 & 0.900 & 0.862 \\
Hedonic Motivation & 0.703 & 0.876 & 0.789 \\
Price Value & 0.659 & 0.906 & 0.870 \\
Habit & 0.720 & 0.911 & 0.870 \\
Behavioral Intention & 0.744 & 0.897 & 0.828 \\
Use Behavior & 0.720 & 0.885 & 0.805 \\
\hline
\end{tabular}

Berdasarkan Tabel 3 dapat diketahui AVE bernilai terendah 0.644 pada variabel facilitating conditions. Variabel mempunyai validitas diskriminan yang baik yakni variabel bernilai AVE diatas 0,5 (Ghozali, 2014). Peubah disebut reliabel ketika skor composite reliability serta Cronbach's Alpha lebih dari 0,7 dan 0,6 (Eisingerich \& Rubera, 2010). Seluruh skor composite reliability dengan nilai terendah 0.876 pada variabel hedonic motivation, sama 
halnya dengan Cronbach's Alpha. Seluruh variabel yang dimoderasi age, gender, dan experience dari nilai AVE hingga Cronbach's Alpha bernilai sebesar 1.000. Maka, seluruh indikator dan variabel dinyatakan valid dan reliabel.

Analisis Skor $R$-Square $\left(R^{2}\right)$ dan $Q$-Square $\left(Q^{2}\right)$

Persentase variance melalui skor $R^{2}$ dapat memaparkan dampak antara konstruk independen dengan dependen dan besar dampaknya secara simultan berkategori 0,67 tinggi, 0,33 sedang, serta 0,19 rendah. Skor $R^{2}$ ditinjau dari $R$ Square Adjusted peubah dependen. Nilai $R^{2}$ keduanya melampaui nilai 0.67 . Maka, kedua variabel tersebut baik dalam memaparkan variasi pada konstruk dengan 0.747 konstruk behavioral intention dan 0.735 konstruk use behavior. Fungsi skor $Q^{2}$ memberi bukti peubah memiliki relevansi prediktif dengan standar $Q^{2}>0$. Ketika skor $Q^{2}<0$, maka model kurang bernilai relevansi prediktif (Ghozali, 2014). Semakin mendekati 1, semakin baik pula model tersebut. Seluruh skor mencapai standar dengan nilai terendah 0.333 pada indikator PE1. Maka tiap variabel dan indikator terbukti memiliki relevansi prediktif.

\section{Analisis Nilai Effect Size $\left(\boldsymbol{f}^{2}\right)$, Path Coefficients (Koefisien Jalur), dan Uji Hipotesis}

Nilai $f^{2}$ berfungsi melihat tingkat kebaikan model serta memprediksi dampak manifes terhadap peubah laten pada struktur model bernilai ambang 0,02 (rendah), 0,15 (sedang), serta 0,35 (tinggi). Nilai kurang dari 0,02 dapat tidak dihiraukan. Jika path coefficient bernilai (+) maka variabel berdampak positif, dan sebaliknya (Hair, Hult, Ringle, \& Sarstedt, 2017). Fungsi path coefficient untuk melihat seberapa besar dampak peubah laten. Nilai $f^{2}$, path coefficient, serta T Statistic mampu ditinjau dalam Tabel 4.

Tabel 4. Skor $f^{2}$, Path Coefficients, dan T Statistics

\begin{tabular}{cccc}
\hline Pengaruh & $\boldsymbol{f}^{2}$ & Path Coefficients & T Statistics \\
\hline Performance Expectancy -> Behavioral Intention & 0.000 & 0.007 & 0.051 \\
Effort Expectancy -> Behavioral Intention & 0.001 & 0.033 & 0.552 \\
Social Influence -> Behavioral Intention & 0.100 & 0.321 & $\mathbf{4 . 4 4 5}$ \\
Facilitating Conditions -> Behavioral Intention & 0.000 & 0.005 & 0.064 \\
Facilitating Conditions -> Use Behavior & 0.086 & 0.261 & $\mathbf{3 . 8 3 2}$ \\
Hedonic Motivation -> Behavioral Intention & 0.019 & 0.129 & 1.794 \\
Price Value -> Behavioral Intention & 0.090 & 0.350 & $\mathbf{3 . 6 8 2}$ \\
Habit -> Behavioral Intention & 0.009 & 0.112 & 1.283 \\
Habit -> Use Behavior & 0.396 & 0.563 & $\mathbf{7 . 8 3 7}$ \\
Behavioral Intention -> Use Behavior & 0.016 & 0.099 & 0.952 \\
age (FC) -> Behavioral Intention & 0.000 & -0.037 & 0.220 \\
age (HM) -> Behavioral Intention & 0.013 & -0.210 & 1.503 \\
age (PV) -> Behavioral Intention & 0.003 & -0.067 & 0.699 \\
age (Hb-BI) -> Behavioral Intention & 0.011 & 0.268 & 1.406 \\
age (Hb-UB) -> Use Behavior & 0.002 & 0.059 & 0.824 \\
gender (FC) -> Behavioral Intention & 0.000 & -0.014 & 0.152 \\
gender (HM) -> Behavioral Intention & 0.009 & 0.074 & 1.447 \\
gender (PV) -> Behavioral Intention & 0.001 & -0.037 & 0.529 \\
gender (Hb-BI) -> Behavioral Intention & 0.000 & 0.004 & 0.045 \\
gender (Hb-UB) -> Use Behavior & 0.001 & 0.014 & 0.384 \\
exp (FC) -> Behavioral Intention & 0.000 & -0.002 & 0.015 \\
exp (HM) -> Behavioral Intention & 0.016 & 0.236 & 1.711 \\
exp (Hb-BI) -> Behavioral Intention & 0.005 & -0.180 & 0.959 \\
exp (Hb-UB) -> Use Behavior & 0.000 & -0.030 & 0.417 \\
\hline
\end{tabular}


Berdasarkan Tabel 4 dapat diketahui hipotesis yang diterima dan ditolak, diantaranya:

H1: PE berdampak positif terhadap BI secara signifikan

Performance expectancy tidak berpengaruh signifikan sebab nilai $T$ Statistic 0.051 lebih kecil dari T Table 1.966. Maka, hipotesis H1 ditolak.

H2: EE berpengaruh positif terhadap BI secara signifikan

Effort expectancy tidak berpengaruh signifikan sebab nilai $T$ Statistic 0.552 lebih kecil dari $T$ Table 1.966. Maka, hipotesis $\mathbf{H 2}$ ditolak.

H3: SI berdampak positif pada BI secara signifikan

Social influence berdampak positif dari path coefficient sebesar 0.321. Sementara nilai $T$ Statistic 4.445 diatas 1.966 yang berarti aspek ini berdampak signifikan pada behavioral intention. Maka, hipotesis $\mathbf{H 3}$ diterima. Hal ini sesuai dengan penelitian (Prasetyo, 2017; Issaramanoros, Khlaisang, \& Pugsee, 2018; Zaini, Hamad, \& Najim, 2020). Aspek ini diukur terhadap orang lain berdampak dalam penggunaan TI. Hal yang dapat dilakukan adalah sosialisasi pada pengguna agar bersedia mengajak atau menyarankan menggunakan sistem ketika bekerja.

H4: FC berpengaruh positif terhadap BI secara signifikan

Facilitating conditions tidak berpengaruh signifikan sebab nilai T Statistic 0.064 lebih kecil dari T Table 1.966. Maka, hipotesis H4 ditolak.

H5: HM berpengaruh positif terhadap BI secara signifikan

Hedonic motivation aspek tidak berpengaruh signifikan sebab nilai T Statistic 1.794 lebih kecil dari T Table 1.966. Maka, hipotesis $\mathrm{H5}$ ditolak.

H6: PV berdampak positif pada BI secara signifikan

Price value berdampak positif dari path coefficient sebesar 0.350. Sementara nilai T Statistic 3.682 diatas 1.966 yang berarti aspek ini berdampak signifikan pada behavioral intention. Maka, hipotesis $\mathbf{H 6}$ diterima. Hal ini sesuai dengan penelitian (Akbar, Irianto, \& Rofiq, 2018; Nanggong, 2018; Tavares \& Oliveira, 2017). Aspek ini diukur dari keterjangkauan biaya yang dikeluarkan dan kesesuaian dengan nilai manfaat yang diperoleh. Hal yang mampu dilaksanakan ialah meningkatkan lebih banyak nilai manfaat pada sistem yang kemudian disosialisasikan.

H7: Hb berpengaruh positif terhadap BI secara signifikan

Habit tidak berpengaruh signifikan sebab nilai $T$ Statistic 1.283 lebih kecil dari $T$ Table 1.966. Maka, hipotesis $\mathbf{H 7}$ ditolak.

H8: FC berdampak positif pada UB secara signifikan

Facilitating conditions berdampak positif dari path coefficient sebesar 0.261. Sementara nilai T Statistic 3.832 diatas 1.966 yang berarti aspek ini berdampak signifikan pada use behavior. Maka, hipotesis $\mathbf{H 8}$ diterima. Hal ini sesuai dengan penelitian (Butarbutar \& Haryanto, 2017; Yalina \& Iriawan, 2011; Nugraha \& Yadnyana, 2018). Aspek ini diukur dari keadaan eksternal yang melingkupi fasilitas keadaan resource serta teknologi. Hal yang dapat dilakukan adalah senantiasa menyediakan dan merawat fasilitas dukungan dalam menggunakan sistem.

H9: Hb berdampak positif pada UB secara signifikan

Habit berdampak positif dari path coefficient sebesar 0.563. Sementara nilai T Statistic 7.837 diatas 1.966 yang berarti aspek ini berdampak signifikan pada use behavior. Maka, hipotesis H9 diterima. Hal ini sesuai dengan penelitian (Pertiwi \& Ariyanto, 2017; Palos-Sanchez \& Saura, 2018; Moura, Gosling, Christino, \& Macedo, 2017). Aspek ini diukur dari tingkat pengguna terbiasa dalam menggunakan sistem baru. Hal yang mampu dilaksanakan ialah menyediakan fitur-fitur yang mengharuskan pegawai terbiasa menggunakan sistem.

H10: BI berpengaruh positif terhadap UB secara signifikan

Behavioral intention tidak berpengaruh signifikan sebab nilai T Statistic 0.952 lebih kecil dari T Table 1.966. Maka, hipotesis H10 ditolak. 
H11: Age, gender, dan experience memperkuat pengaruh FC terhadap BI

$T$ Statistic age 0.220 ; gender 0.152 ; experience 0.015 berarti ketiganya tidak berpengaruh signifikan (tidak memperkuat pengaruh FC -> BI) sebab <1.966. Maka, hipotesis $\mathrm{H11}$ ditolak.

H12: Age, gender, dan experience memperkuat pengaruh HM terhadap BI

$T$ Statistic age 1.503; gender 1.447; experience 1.711 berarti ketiganya tidak berpengaruh signifikan (tidak memperkuat pengaruh HM -> BI) sebab <1.966. Maka, hipotesis $\mathrm{H12}$ ditolak.

H13: Age dan gender memperkuat pengaruh PV terhadap BI

$T$ Statistic age 0.699; gender 0.529 berarti keduanya tidak berpengaruh signifikan (tidak memperkuat pengaruh PV -> BI) sebab <1.966. Maka, hipotesis H13 ditolak.

H14: Age, gender, experience memperkuat pengaruh $\mathrm{Hb}$ terhadap BI

$T$ Statistic age 1.406; gender 0.045 ; experience 0.959 berarti ketiganya tidak berpengaruh signifikan (tidak memperkuat pengaruh $\mathrm{Hb} \rightarrow \mathrm{BI}$ ) sebab <1.966. Maka, hipotesis $\mathrm{H14}$ ditolak.

H15: Age, gender, experience memperkuat pengaruh Hb terhadap UB

$T$ Statistic age 0.824 ; gender 0.384 ; experience 0.417 berarti ketiganya tidak berpengaruh signifikan (tidak memperkuat pengaruh $\mathrm{Hb} \rightarrow \mathrm{UB}$ ) sebab <1.966. Maka, hipotesis $\mathrm{H15}$ ditolak.

\section{SIMPULAN}

Aspek-aspek yang berdampak pada penerimaan modul Kepegawaian SIESTA yakni social influence, facilitating conditions, price value, dan habit. Di lain sisi, perbedaan dan kesenjangan umur, jenis kelamin, serta masa kerja tidak memperkuat dampak terhadap penerimaan. Hasil penelitian mampu menjadi kontribusi agar penerimaan dapat ditingkatkan dengan memperhatikan aspek yang berdampak. Bagi pihak rumah sakit agar menjadikan feedback dalam mengembangkan dan menerapkan sistem. Bagi penelitian selanjutnya dapat dilakukan penelitian pada modul-modul SIESTA lainnya atau sistem rumah sakit lain dengan proportionate stratified random sampling agar mewakili tiap kategori.

\section{REFERENSI}

Akbar, M. R., Irianto, G., \& Rofiq, A. (2018). Purchase Behaviour Determinants on Online Mobile Game in Indonesia. International Journal of Multicultural and Multireligious Understanding, 5(6), 16-27.

Bloch, M., Blumber, S., \& Laartz, J. (2012). Delivering large-scale IT projects on time, budget and value. McKinsey Quarterly.

Butarbutar, F. T. S., \& Haryanto, Y. (2017). Kajian Signifikansi Faktor yang Mempengaruhi Penggunaan E-Learning pada Siswa SMK Global Informatika Tangerang. Jurnal RESTI, 1 No. 1, 9-18.

Eisingerich, A. B., \& Rubera, G. (2010). Drivers of Brand Commitment: A Cross National Investigation. Journal of International Marketing, 18 (2), 27.

Geldmacher, W., Just, V., Kirschner, C., Buchmuller, M., \& Marquardt, K. (2017). The Correlation of Information and Knowledge in Regard to The Acceptance Level and Their Implication on Self-Driving Cars in Germany. Ecoforum Journal, 6 No. 13(3).

Ghozali, I. (2014). Structural Equation Modeling Metode Alternatif dengan Partial Least Squares (PLS). Semarang: Universitas Dipenegoro Semarang.

Hair, J. F., Hult, G. T. M., Ringle, C. M., \& Sarstedt, M. (2017). A Primer on Partial Least Squares Structural Equation Modeling (PLS-SEM) 2nd Edition. California: SAGE.

Issaramanoros, E., Khlaisang, J., \& Pugsee, P. (2018). Auto Mechanic Students' Perceptions and Readiness toward Mobile Learning in Thailand. International Journal of Interactive 
Mobile Technologies, 12 (5), 28-42.

Moura, A. C. de, Gosling, M. de S., Christino, J. M. M., \& Macedo, S. B. (2017). Acceptance and Use of Technology by Older Adults for Choosing A Tour-ism Destination: A Study Using UTAUT2. Brazilian Journal of Tourism Research, 11 (2), 239-269.

Mutlu, H. M., \& Der, A. (2017). Unified Theory of Acceptance and Use of Technology: The Adoption of Mobile Messaging Application. International Scientific Conference on Economic and Social Development, 14 (1), 169-186.

Nanggong, A. (2018). Perilaku Pasca-Adopsi Teknologi Personal terhadap Intensi Perilaku Berkelanjutan. Jurnal Manajemen Teknologi, 17 (1), 10-26.

Nugraha, S., \& Yadnyana, K. (2018). Penerapan Model UTAUT dalam Menjelaskan Faktor Minat dan Penggunaan Sistem Informasi Manajemen Daerah. E-Jurnal Akuntansi Universitas Udayana, 24 (2), 959-987.

Palos-Sanchez, P., \& Saura, J. R. (2018). The Effect of Internet Searches on Afforestation: The Case of A Green Search Engine. Forests, 9 (51), 1-24.

Pertiwi, N. W. D. M. Y., \& Ariyanto, D. (2017). Penerapan Model UTAUT2 untuk Menjelaskan Minat dan Perilaku Penggunaan Mobile Banking di Kota Denpasar. EJurnal Akuntansi Universitas Udayana, 18 (2), 1369-1397.

Prasetyo, D. Y. (2017). Penerapan Metode UTAUT (Unified Theory of Acceptance and Use of Technology) dalam Memahami Penerimaan dan Penggunaan Website KKN LPPM UNISI. Jurnal SISTEMASI, 6 (2), 26-34.

Quadahi, J. (2008). A Qualitative Analysis of Factors Associated with User Acceptance and Rejection of a New Workplace Information System in the Public Sector: A Conceptual Model. Canadian Journal of Administrative Sciences, 201-213.

Samaradiwakara, G. D. M. N., \& Gunawardena, C. G. (2014). Comparison of Existing Technology Acceptance Theories and Models to Suggest A Well Improved Theory/Model. International Technical Sciences Journal, 1 (1), 21-36.

Tavares, J., \& Oliveira, T. (2017). Electronic Health Record Portal Adoption: A Cross Country Analysis. BMC, 17 (97), 1-17.

Venkatesh, V., Morris, M. G., Davis, G. B., \& Davis, F. D. (2003). User Acceptance of Information Technology: Toward A Unified View. MIS Quarterly: Management Information Systems, 27 (3), 425-478.

Venkatesh, V., Thong, J. Y. L., \& Xu, X. (2012). Consumer Acceptance and Use of Information Technology: Extending the Unified Theory of Acceptance and Use of Technology. MIS Quarterly: Management Information Systems, 36 (1), 157-178.

Wonjun, L., \& Shin, S. (2019). An Empirical Study of Consumer Adoption of Internet of Things Services. International Journal of Engineering and Technology Innovation, 9(1), $01-11$.

Yalina, N., \& Iriawan, N. (2011). Evaluasi Penerapan Sistem Informasi Perencanaan Pembangunan Daerah Pemerintah Provinsi Jawa Timur Menggunakan Metode TAM. Prosiding Seminar Nasional Manajemen Teknologi XIV, (978-602-97491-3-7), 1-8.

Zaini, W. H. A., Hamad, M. K., \& Najim, A. S. (2020). Factors Affecting The Adoption of An Accounting Information System Based on UTAUT2 and Its Implementation in A Tourism Corporation. African Journal of Hospitality, Tourism and Leisure, 9 (1), 1-14. 